\begin{tabular}{|c|c|c|}
\hline \multirow{3}{*}{$\begin{array}{r}\text { Case Reports in } \\
\text { Gastroenterology }\end{array}$} & \multirow{2}{*}{\multicolumn{2}{|c|}{ Case Rep Gastroenterol 2013;7:352-357 }} \\
\hline & & \\
\hline & $\begin{array}{l}\text { DOI: 10.1159/000354974 } \\
\text { Published onlIne: August 24, } 2013\end{array}$ & $\begin{array}{l}\text { ○ } 2013 \text { S. Karger AG, Basel } \\
\text { 1662-0631/13/0072-0352 } \$ 38.00 / 0 \\
\text { www.karger.com/crg }\end{array}$ \\
\hline & \multicolumn{2}{|c|}{$\begin{array}{l}\text { This is an Open Access article licensed under the terms of the Creative Common } \\
\text { Attribution-NonCommercial } 3.0 \text { Unported license (CC BY-NC) (www.karger.com/OA } \\
\text { license), applicable to the online version of the article only. Distribution permitted for non } \\
\text { commercial purposes only. }\end{array}$} \\
\hline
\end{tabular}

\title{
Tumor-Like Growth of Giant Inflammatory Polyposis in a Patient with Ulcerative Colitis
}

\author{
Makoto Nagashima $^{a}$ Yui Sugishita ${ }^{a}$ Ayako Moriyama $^{a}$ \\ Mitsuru Ooshiro $^{a}$ Kengo Kadoya $^{a}$ Ayami Sato $^{a}$ Tomoaki Kitahara $^{a}$ \\ Ryuichi Takagi $^{a}$ Tasuku Urita $^{a}$ Yutaka Yoshida $^{a}$ Hiroshi Tanaka $^{a}$ \\ Takashi Oshiro $^{a}$ Kentaro Nakamura ${ }^{b}$ Yasuo Suzuki ${ }^{b}$ Nobuyuki Hiruta $^{c}$ \\ Shinichi Okazumi ${ }^{a}$ Ryoji Katoh ${ }^{a}$ \\ Departments of ${ }^{a}$ Surgery, ${ }^{b}$ Internal Medicine and ${ }^{c}$ Pathology, Toho University Sakura \\ Medical Center, Sakura, Japan
}

\section{Key Words}

Giant inflammatory polyposis $\cdot$ Filiform polyposis $\cdot$ Ulcerative colitis $\cdot$ Inflammatory bowel disease

\begin{abstract}
We report a unique case of giant obstructing inflammatory polyposis associated with ulcerative colitis (UC). A 25-year-old Japanese man with an UC history of 2 years and 6 months was referred to our institution because of diarrhea and melena. His computed tomography scan showed marked dilation of the transverse and descending colon; therefore, we performed total colectomy. Macroscopic evaluation of the excised specimen indicated constricting lesions with giant polyposis in the transverse and descending colon. The polyposis consisted of narrow worm- or noodle-like polyps that bridged over the irregular ulcers. Histologic evaluation of the excised specimen indicated transmural inflammation with a thickened proper muscular layer overlaid with inflammatory polyposis. Based on these data, a diagnosis of giant inflammatory polyposis should be considered in patients who have had UC. Although giant inflammatory polyposis is considered benign, surgical treatment may be indicated to avoid serious complications.

(c) 2013 S. Karger AG, Basel
\end{abstract}


Nagashima et al.: Tumor-Like Growth of Giant Inflammatory Polyposis in a Patient with Ulcerative Colitis

\section{Introduction}

Giant inflammatory (filiform) polyposis is an uncommon benign lesion and is usually associated with inflammatory bowel disease (IBD). Long-term inflammation of the colonic mucosa during chronic IBD with alternating periods of ulceration and healing may lead to the formation of finger-like projections $[1,2]$. In rare cases, a giant inflammatory polyposis forms a large tumor mass [3-7]. On colonoscopy and radiologic studies, numerous filiform polyps appear as a 'mass of worms' or as a 'fungating mass'; hence, this condition is easily confused with cancer. Inflammatory polyps or pseudopolyps are the most common lesions observed both in ulcerative colitis (UC) and Crohn's disease (CD) [8-12]. Moreover, in some cases, the polyps contain both mucosal and submucosal tissue, indicating initial inflammatory involvement of the deeper bowel layers. These polyps often appear finger-like and are hence named filiform polyps. They are composed of a central core of submucosal connective tissue coated by normal, non-inflamed mucosa. Here, we report the case of a patient with UC with large tumors obstructing the transverse and descending colon, who presented with severe diarrhea and melena.

\section{Case Report}

A 25-year-old Japanese man with an UC history of 2 years and 6 months was successfully treated with prednisolone. The disease was in remission and his symptoms had been relieved. However, the disease flared up and the patient was admitted to our hospital because of severe abdominal pain and bloody diarrhea. Physical examination revealed direct soreness and masses in the upper and left lower abdominal sites. Blood examination revealed anemia (hemoglobin level $5.5 \mathrm{~g} / \mathrm{dl}$ [normal 11.5-15.0]), hypoproteinemia (protein level $4.6 \mathrm{~g} / \mathrm{dl}$ [normal 6.7-8.3]) and hypoalbuminemia (albumin level $1.9 \mathrm{~g} / \mathrm{dl}$ [normal 3.8-5.3]).

Computed tomography (CT) imaging showed bowel wall thickening of the transverse and descending colon, which raised suspicion of wall thickening of several segments of the small bowel. The CT scan also demonstrated localized high-density areas in the lumen of the transverse and descending colon (fig. 1a). Barium enema examination showed irregular mucosal contours with polyposis in these areas (fig. 1b). A colonoscopy revealed a large mass with numerous white-pale reddish polyps of complex shape in the descending colon. The endoscope could not be inserted beyond this point. Endoscopy indicated that the colon distal to the mass and the rectum were normal. Based on this examination, colon carcinoma was strongly suspected, and several biopsies were performed. Histology of the examined sections indicated uncharacteristic inflammatory changes in the mucosa, but no cellular dysplasia. Subsequently, the patient underwent a total colectomy for removal of the obstruction. His postoperative recovery was complete, and he remains in good health.

Macroscopic examination of the excised colon indicated remarkable dilation. On excision, we observed one tumor measuring $23 \times 18 \mathrm{~cm}$ in the transverse colon and another measuring $14 \times 13 \mathrm{~cm}$ in the descending colon. There were no obvious areas of ulceration, although each tumor had a coral-reef-like surface with numerous soft, finger-like polyps (up to $5 \mathrm{~cm}$ in diameter) projecting into the lumen. These aggregating polyps occurred in the segment with the thickened wall. The cross-section of the tumors showed that narrow strings of tissue were interconnected, forming multiple, variably sized spaces inside the tumors (fig. 2). The surrounding fat tissue was unaffected, and no suspicious lymph nodes were detected. 
Nagashima et al.: Tumor-Like Growth of Giant Inflammatory Polyposis in a Patient with Ulcerative Colitis

Microscopic examination revealed that the tumors comprised strings of fibrotic connective tissue, lined by inflamed colonic mucosa, and the surrounding spaces were filled with fecal and mucoid materials. A fibrovascular core and inflammatory polyposis were evident from the submucosa to the proper muscular layer and the submucosa had partially disappeared in both the elevated and the depressed lesions. The polyps contained regenerative and hyperplastic muscularis mucosa with an arborized and thickened configuration (fig. 3a, b). In most areas, the crypt architecture was normal, and no epithelial atypia of the polyps was noted. The mucosal inflammation consisted of lymphocytes, plasma cells, eosinophils and lymphoid follicles. Neutrophil infiltration, cryptitis, crypt abscess, which is characteristic of active UC, and Paneth cell metaplasia were found in the transverse colon (fig. 3c, d). Sections through the bowel wall near the mass showed colonic mucosa with regenerative features, including architecturally mildly distorted glands, but without active inflammatory changes (fig. 3e). There were no granulomas or parasites. Finally, histopathological examination of the resected colon led to the diagnosis of giant inflammatory (filiform) polyposis associated with UC.

\section{Discussion}

Inflammatory polyps are a common complication in patients with IBDs such as UC and CD, accounting for approximately $10-20 \%$ of all cases. Inflammatory polyps may originate from the regenerative mucosa in the remission stage after an acute recurrence of UC or CD. In rare cases, numerous large-sized polyps are present, and this condition is known as giant inflammatory (filiform) polyposis [8-12]. These polyps are associated with CD in approximately two-thirds of cases and with UC in one-third of cases. Giant inflammatory polyposis can be localized in one segment of the colon, or numerous polyps can be diffusely involved in the entire colon. The transverse colon is the most common site, followed by the sigmoid and descending colon, the cecum and the splenic and hepatic flexures [13]. In our case, two masses of giant inflammatory polyposis were located in the transverse and descending colon.

The clinical features of the reported cases indicate that the time from the initial diagnosis of UC to confirmation of giant inflammatory polyposis ranged from 3 to 276 months [6]. In our patient, this interval was 30 months. Patients may present with various symptoms, including anemia, weight loss, cramping abdominal pain, diarrhea, passage of blood through the rectum and colonic obstruction. Most patients go undiagnosed until they develop signs and symptoms of obstruction, hemorrhage and anemia [1,2, 14].

The pathogenesis of giant inflammatory polyposis is considered to result from enlarged mucosal tags, caused by repeated peristalsis and fecal stream. Giant inflammatory polyposis may be related to postinflammatory regeneration or hyperplastic proliferation of the colonic mucosa between ulcerations. The histopathological features include inflammatory infiltrates overlying the muscularis mucosae, deep fissure-like ulcers, chronic mucosal inflammation with lymphoid hyperplasia and nerve hyperplasia in the surrounding mucosa $[1,2,4-6,15]$. Giant inflammatory polyposis in UC may be a consequence of severe inflammation rather than of increased duration of the disease.

In summary, we present the case of a Japanese patient with UC who was diagnosed with giant inflammatory polyposis localized in the transverse and descending colon. Severe ulcerative inflammation and its repair process may have caused the development of the giant inflammatory polyps. 
Nagashima et al.: Tumor-Like Growth of Giant Inflammatory Polyposis in a Patient with Ulcerative Colitis

\section{Acknowledgements}

We thank Dr. Masanori Tanaka (Hirosaki Municipal Hospital) for his evaluation of the histopathological specimens.

\section{References}

1 Rozenbajgier C, Ruck P, Jenss H, et al: Filiform polyposis: a case report describing clinical, morphological, and immunohistochemical findings. Clin Investig 1992;70:520-528.

2 Bauknecht KJ, Grosse G, Kleinert J, et al: Filiform polyposis of the colon in chronic inflammatory bowel disease (so-called giant inflammatory polyps). Z Gastroenterol 2000;38:845-846, 848-854.

-3 Fitterer JD, Cromwell LG, Sims JE: Colonic obstruction by giant pseudopolyposis. Gastroenterology 1977;72:153-156.

4 Okayama N, Itoh M, Yokoyama Y, et al: Total obliteration of colonic lumen by localized giant inflammatory polyposis in ulcerative colitis: report of a Japanese case. Intern Med 1996;35:24-29.

5 Hurlstone DP: Large-bowel obstruction secondary to localized rectal giant pseudopolyposis complicating ulcerative colitis: first reported case. Endoscopy 2002;34:1025.

6 Yada S, Matsumoto T, Kudo T, et al: Colonic obstruction due to giant inflammatory polyposis in a patient with ulcerative colitis. J Gastroenterol 2005;40:536-539.

7 Zeki S, Catnach S, King A, et al: An obstructing mass in a young ulcerative colitis patient. World J Gastroenterol 2009;15:877-878.

$\checkmark 8$ Kovalcik PJ, Szydlowski TR: Localized giant pseudopolyposis of the colon in ulcerative colitis. Dis Colon Rectum 1980;23:268-270.

\$ Tajiri T, Tate G, Mitsuya T, et al: Localized giant inflammatory polyposis (filiform polyposis) with diverticula in ulcerative colitis. J Gastroenterol 2003;38:912-914.

10 Koinuma K, Togashi K, Konishi F, et al: Localized giant inflammatory polyposis of the cecum associated with distal ulcerative colitis. J Gastroenterol 2003;38:880-883.

-11 Kosugi I, Tada T, Tsutsui Y, et al: Giant inflammatory polyposis of the descending colon associated with a Crohn's disease-like colitis. Pathol Int 2002;52:318-321.

12 Ryu CB, Kwon KW, Kim JO, et al: Localized giant pseudopolyposis in Crohn's disease. Gastrointest Endosc 2002;55:914.

13 Kelly JK, Langevin JM, Price LM, et al: Giant and symptomatic inflammatory polyps of the colon in idiopathic inflammatory bowel disease. Am J Surg Pathol 1986;10:420-428.

14 Bryan RL, Newman J, Alexander-Williams J: Giant inflammatory polyposis in ulcerative colitis presenting with protein losing enteropathy. J Clin Pathol 1990;43:346-347.

15 Tanaka M, Saito H, Kusumi T, et al: Spatial distribution and histogenesis of colorectal Paneth cell metaplasia in idiopathic inflammatory bowel disease. J Gastroenterol Hepatol 2001;16:1353-1359. 
Nagashima et al.: Tumor-Like Growth of Giant Inflammatory Polyposis in a Patient with Ulcerative Colitis
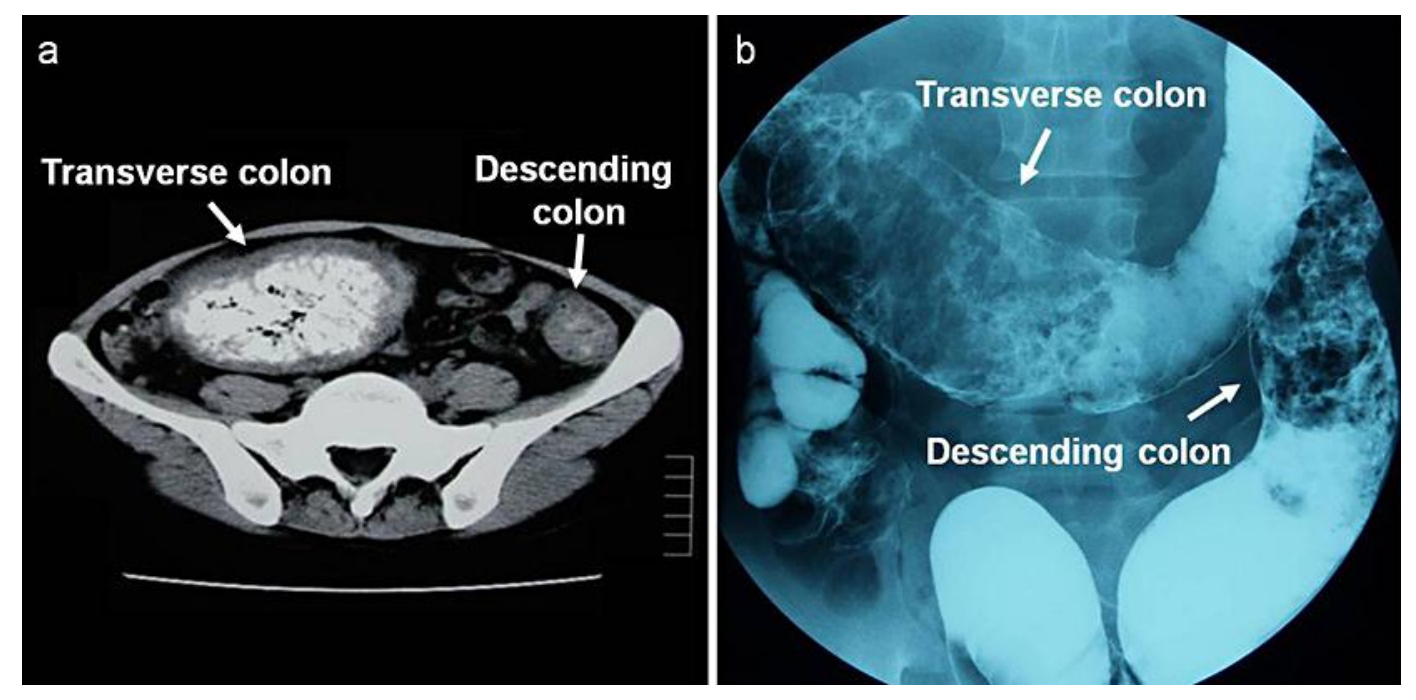

Fig. 1. a Abdominal CT shows marked dilation of the transverse and descending colon with localized highdensity areas. b Barium enema examination shows irregular mucosal contours and barium flecks in the transverse and descending colon.

\section{Descending colon}
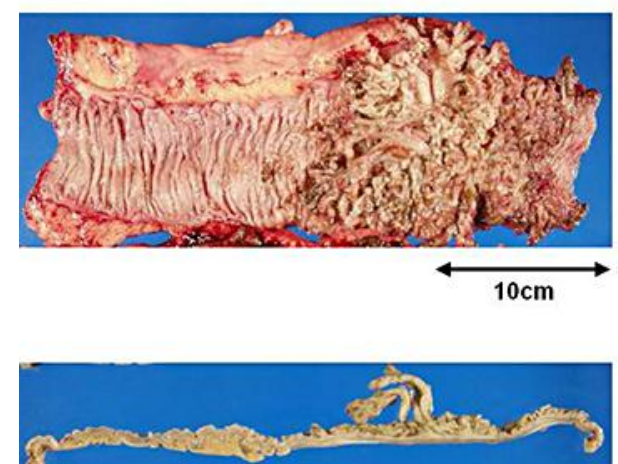

Transverse colon
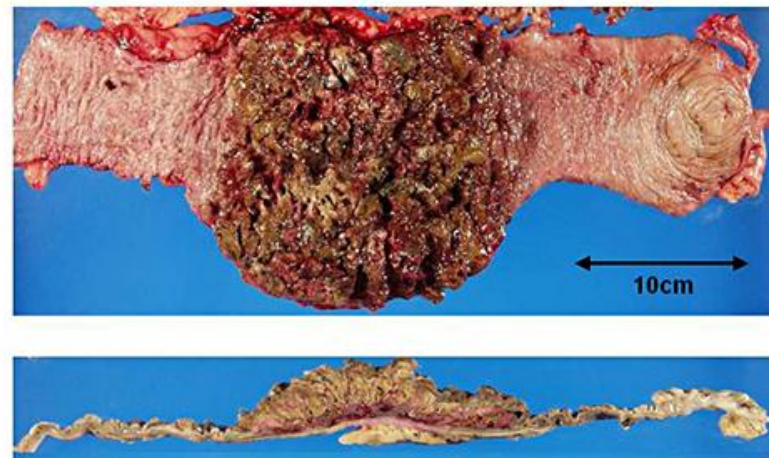

Fig. 2. Macroscopic findings of the resected colon. Numerous finger-like polyps aggregating in the transverse and descending colon are evident. The resected surface shows polyps of various sizes in the epithelial layer. 


\section{Case Reports in \\ Gastroenterology}
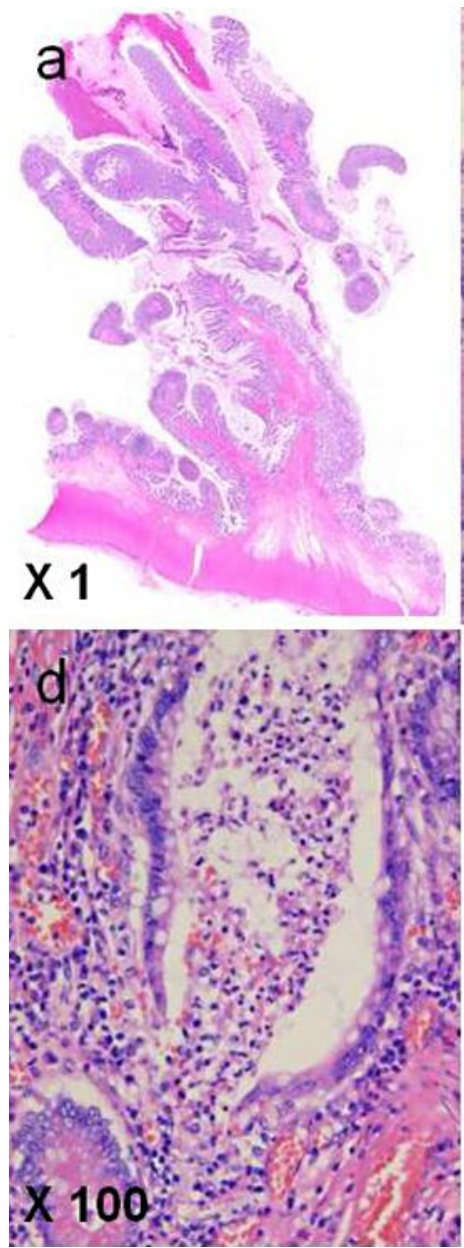

\begin{tabular}{l|l}
\hline \multicolumn{2}{l}{ Case Rep Gastroenterol 2013;7:352-357 } \\
\hline DOI: $10.1159 / 000354974$ & $\begin{array}{l}\text { C 2013 S. Karger AG, Basel } \\
\text { www.karger.com/crg }\end{array}$ \\
\hline
\end{tabular}

Nagashima et al.: Tumor-Like Growth of Giant Inflammatory Polyposis in a Patient with Ulcerative Colitis
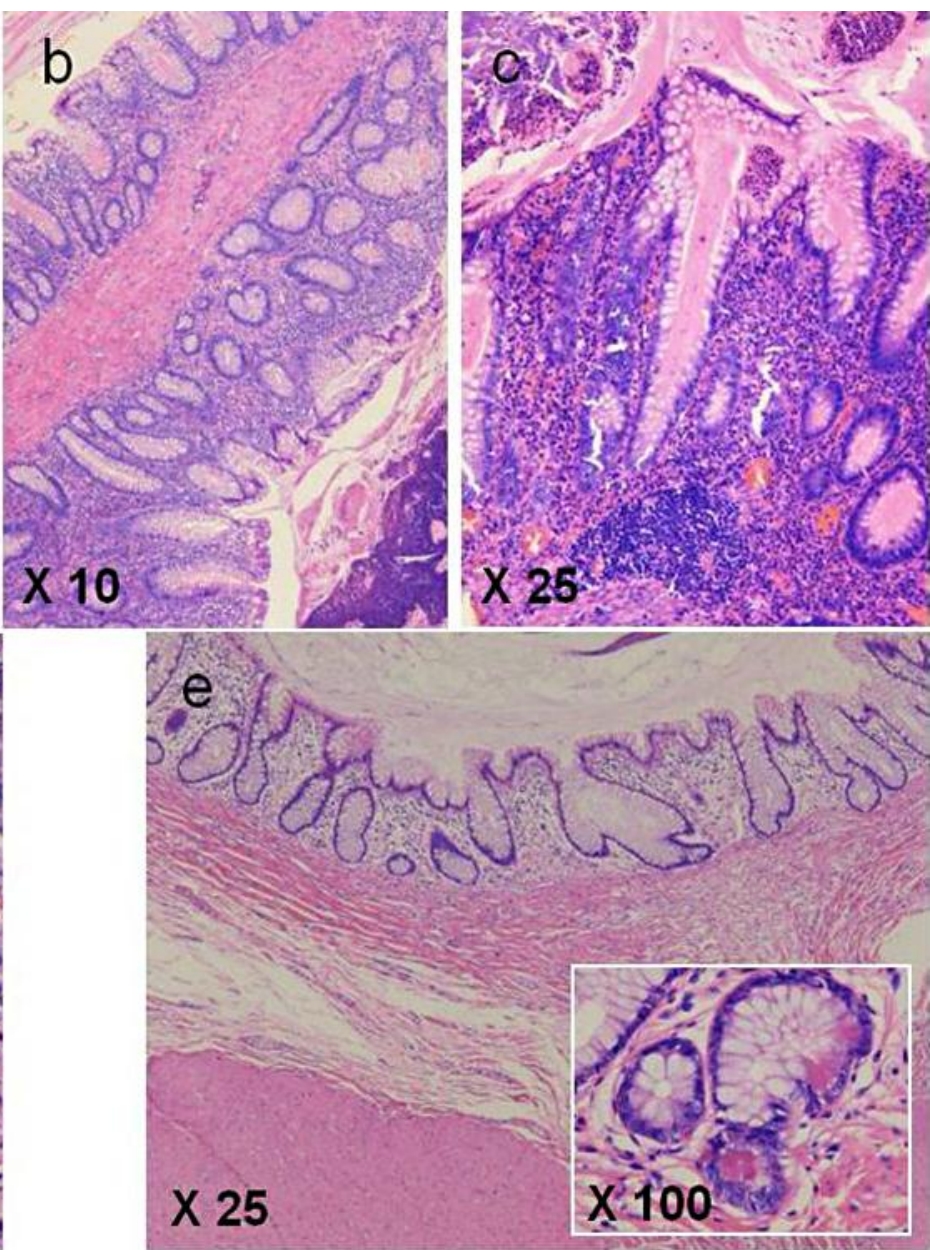

Fig. 3. Several large and small filiform polyps with arborized fibrovascular stromal tissue have formed, and the surrounding spaces are filled with fecal and mucoid materials. a Low-power view. $\mathbf{b}$ High-power view. Active inflammatory lesions accompanied with crypt abscess are found in the mucosa of polyps. The active inflammation is more evident in the transverse colon compared to the descending colon. c Highpower view of active inflammatory lesions. $\mathbf{d}$ Crypt abscess in the transverse colon. e Histologic features of crypt distortion, loss of the muscularis mucosae, submucosal fibrosis and Paneth cell metaplasia (inset) in the transverse and descending colon. These findings are indicative of UC remission. 